\title{
CRIAÇÃO DO GT DE HISTÓRIA DA EDUCAÇÃO NA ANPUH
}

Prezados colegas da Diretoria

da Associação Nacional de História,

No dia 30 de julho de 2015, às 14 horas, reuniram-se nas dependências da Universidade Federal de Santa Catarina, na cidade de Florianópolis, participantes dos simpósios temáticos "STo32 - Culturas escolares e práticas e educativas: escritas, narrativas e usos sociais”, coordenado pelos professores doutores Cláudio de Sá Machado Júnior (Universidade Federal do Paraná) e Doris Bittencourt Almeida (Universidade Federal do Rio Grande do Sul), e "STo56 - História da Educação: entre práticas e representações”, coordenado pelos professores doutores Carlota Boto (Universidade de São Paulo) e Washington Dener dos Santos Cunha (Universidade do Estado do Rio de Janeiro), com a finalidade de deliberar sobre a criação de um GT de História da Educação na ANPUH-Brasil. A iniciativa de proposição contou ainda com Maria Teresa Santos Cunha (Universidade do Estado de Santa Catarina), e cumpre os requisitos existentes no estatuto e no regimento da associação, com atividades já realizadas por dois GTs de âmbito regional, sendo um no Rio Grande do Sul e outro no Paraná.

A criação de um GT de História da Educação demanda da quantidade significativa de pesquisadores sócios da ANPUH-Brasil cujas pesquisas caracterizam-se como de História da Educação, e pode ser verificada numericamente em eventos de grande porte, como o Congresso Brasileiro de História da Educação, promovido pela Sociedade Brasileira de História da Educação, e os simpósios da Associação Nacional de PósGraduação e Pesquisa em Educação (ANPED), em âmbito nacional. Em âmbito internacional, realizam-se eventos de natureza ibero-americana, 
luso-brasileira e o International Standing Conference for History of Education, reunindo anualmente pesquisadores de diversos países.

A criação do GT de História da Educação na ANPUH-Brasil tem por finalidade, além de formalizar uma já existente rede pesquisadores brasileiros, propor a realização de um trabalho contínuo de suas atividades, promovendo debates sobre pesquisas e incentivando a produção científica no campo da História. A criação do GT garante também uma participação contínua nas atividades da ANPUH-Brasil, incluindo aqueles realizados pelas suas seções estaduais.

Caracteriza-se também como uma atividade pretendida pelo GT de História da Educação a publicação de livros, resultado das atividades feitas pelo grupo, e a criação de um periódico online. Acreditamos que a criação do GT no âmbito da ANPUH-Brasil propicie a participação de mais pesquisadores do campo, ampliando espaços e promovendo uma maior integração, além de favorecer produtivos diálogos.

Sem mais para o momento, submetemos este documento à Diretoria da entidade para iniciarmos de imediato os trabalhos deste novo grupo de trabalho. Em anexo, disponibilizamos a lista de nomes, assinaturas e filiações institucionais que respaldam a criação do GT de História da Educação na ANPUH-Brasil.

Cordialmente,

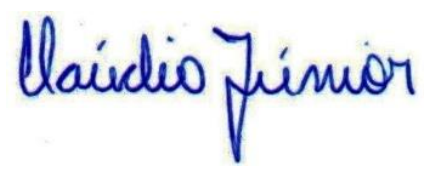

Prof. Dr. Cláudio de Sá Machado Júnior (Universidade Federal do Paraná) - Coordenador do Comitê Científico do GT de História da Educação - ANPUH-Brasil

Prof. $^{a}$ Dr. ${ }^{a}$ Carlota Boto (Universidade de São Paulo); Prof. ${ }^{a}$ Dr. ${ }^{a}$ Doris Bittencourt Almeida (Universidade Federal do Rio Grande do Sul); Prof. ${ }^{a}$ Dr. $^{\text {a }}$ Maria Teresa Santos Cunha (Universidade do Estado de Santa Catarina); Prof. Dr. Washington Dener dos Santos Cunha (Universidade do Estado do Rio de Janeiro)

Florianópolis, 30 de julho de 2015. 